\title{
Necrotising leukoencephalopathy complicating treatment of childhood leukaemia
}

\author{
O ROBAIN, ${ }^{*}$ O DULAC, ${ }^{*}$ JP DOMMERGUES, $\uparrow$ F BERNAUDIN, $\ddagger$ K DIEBLER, $\S$ \\ C KALIFA $\|$ J POIRIER $\|$
}

From Hôpital St Vincent de Paul, Paris; * Hôpital Parrot, Bicêtre; † Hôpital Intercommunal, Créteil; $\ddagger$ Hôpital Foch, Suresnes; § Institut Gustave Roussy, Villejuif; \|Hôpital Henri Moridor, Créteil, \ France

\begin{abstract}
SUMMARY Nine children treated for acute leukemia or lymphosarcoma developed subacute encephalopathy starting with listlessness, depression and impairment of speech. Walking difficulties, ataxia, spasticity and sphincter disorders developed later. Transient intracranial hypertension and abnormal movements respectively developed in two patients. EEG frontal slow waves, raised CSF protein, abnormal white matter radioisotope uptake and CT scan hypodensity with patchy contrast enhancement were evident at the onset. Later, dilated ventricles and calcification appeared in the younger patients. Post-mortem neuropathological studies of three patients disclosed predominantly perivascular myelin loss in areas of white matter necrosis, abnormalities of small vessels and numerous axonal swellings. The spinal cord showed secondary degeneration of the corticospinal tracts. Analysis of the aetiological factors in this series points to the prevailing danger of cranial radiotherapy, probably increased by the young age of patients and by associated drug administration.
\end{abstract}

Great improvement in survival has resulted from the contemporary treatment of acute leukemia. However, this has been associated with the appearance of various previously unobserved neurological complications that have recently been reviewed. ${ }^{12}$ Since the first report by Kay et al,${ }^{3}$ many papers have dealt with the problem of subacute necrotising leukoencephalopathy. ${ }^{4-7} \mathrm{~A}$ recent symposium on the subject indicated the importance of the subject (Rome 1981) and the difficulties of clinical diagnosis and of the aetiology. Clinicopathological observations are rare $;^{7-9}$ and cerebral biopsies recently have been reported. ${ }^{10}$ We describe nine patients who developed this complication.

\section{Patients}

The series comprised nine children followed from 1970 to 1981 for acute leukemia (eight cases) or lymphosarcoma (one case). Detailed case reports have previously been reported concerning patients 3,4 and 5." The drugs administered included prednisone, vincristine,

Address for reprint requests: Dr O Dulac, Clinique de Pédiatre, Hôpital St Vincent de Paul, 74 Av. Denfert Rochereau, 75674 Paris Cedex 14, France

Received 18 February 1983 and in revised form 4 July 1983 Accepted 17 July 1983 rubidomycine, cyclophosphamide, aracytine and L-asparaginase. Meningeal prophylaxis included intrathecal methotrexate in patients $3,4,5,7$ and 9 and cranial irradiation in all patients (fig 1). For leukemia, maintenance treatment included orally administered methotrexate and 6-mercaptopurine. In addition, two patients received supplementary cranial irradiation. Patient 7 received $20 \mathrm{~Gy}$ and later $10 \mathrm{~Gy}$ in fractionated doses because of meningeal relapse. Patient 9 received $10 \mathrm{~Gy}$ in a single dose before bone marrow transplantation (fig 1).

\section{Methods}

For all children, repeated neurological examinations were performed by one of us. Neuroradiological studies included technetium brain scan in four patients, cerebral angiography for one and CT scan for six. CT was repeated during the follow-up of two patients. Cerebrospinal fluid (CSF) studies included detailed viral serology for all patients including measles, herpes, cytomegalovirus, mononucleosis, mumps, poliomyelitis, protein index and electrophoresis ${ }^{12}$ in six patients, and the level of basic protein $^{13}$ in four patients. Post-mortem neuropathological study of the brain was performed in three patients, including the spinal cord in two.

\section{Results}

The series included five girls and four boys aged 2 


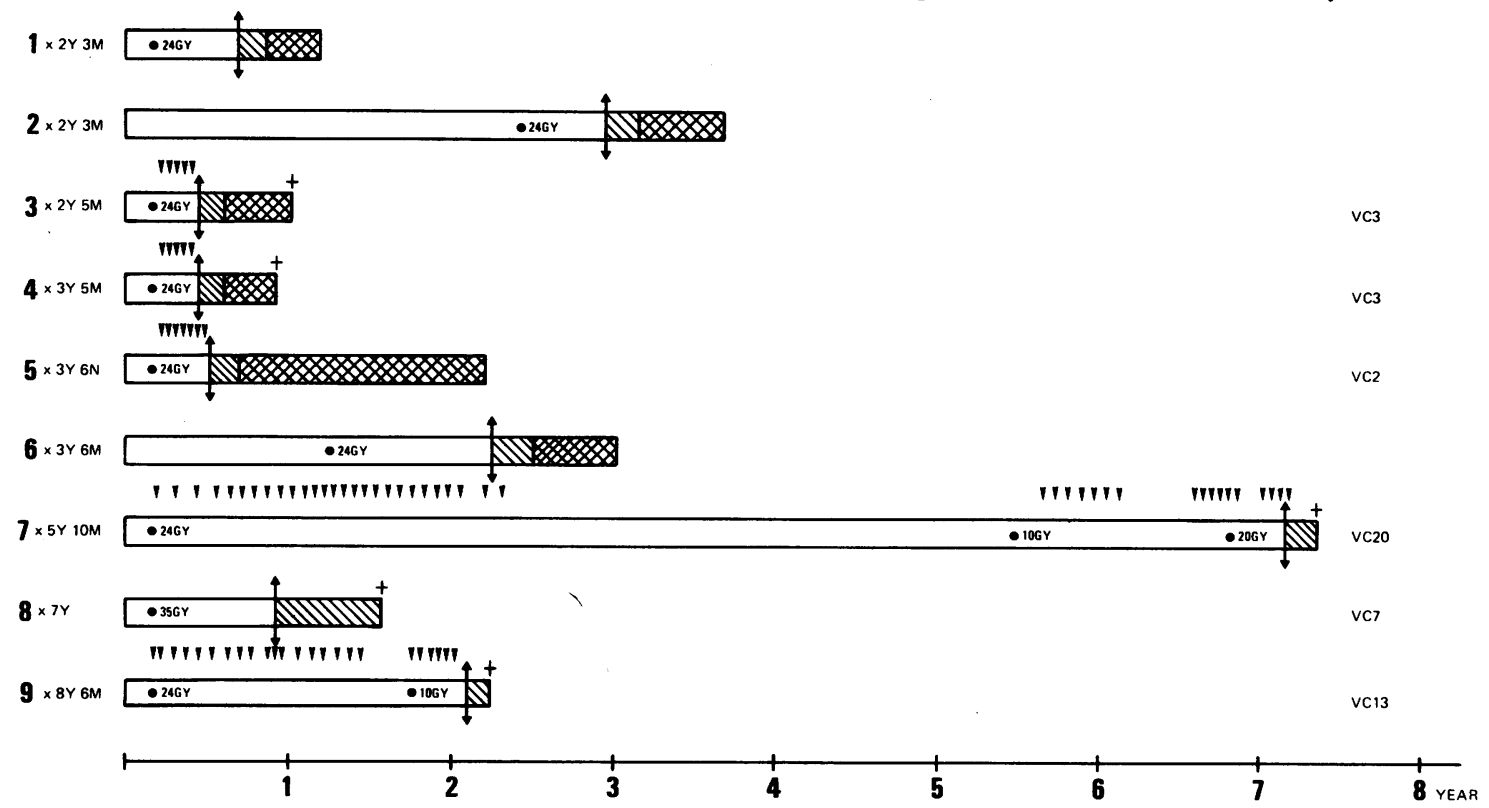

Fig 1 Follow-up of the 9 patients. Notice lack of detailed knowledge concerning chemotherapy of patients $n^{\circ} 1,2$ and 6.

years 3 months to 8 years 6 months at onset of the haematological disease, and 2 years 10 months to 13 years 3 months when the first signs of the neurological complication appeared. The delay from onset of the haematological treatment to appearance of the encephalopathy ranged from 5 months to 7 years 5 months (fig 1).

\section{CLINICAL SIGNS}

In nine patients the onset was rapid enough for the parents to specify the day or week when the disease started. The first signs appeared without fever, and consisted of behavioural disorders including depression with unexplained bursts of tears, listlessness, reduction of speech and drowsiness. These symptoms progressively worsened over a period of a few weeks, the child becoming mute, akinetic and indifferent. By that time, instability of gait appeared and examination elicited pyramidal and cerebellar signs. Involuntary micturition was frequent. Increasing swallowing difficulties appeared later, as a result of pseudo-bulbar palsy.

In two patients, abnormal movements were observed soon after onset of the disease, consisting of slow involuntary athetoid movements with distal predominance. Although initially unilateral, they soon extended to both sides. Abnormal postures with opisthotonus and head retraction could also be observed. These phenomena increased as the child cried. During a period of 1 to 2 months, these symptoms progressively worsened and, in two patients, transient clinical and ophthalmological signs of intracranial hypertension appeared-vomiting, drowsiness and papilloedema.

\section{LABORATORY AND RADIOLOGICAL STUDIES} Lymphopenia and hypogamma-globulinaemia were not observed in any case. From the onset of the first clinical signs, diffuse but predominantly frontal delta slow waves were recorded in the EEG of all patients. In five patients, CSF transudative protein increased, ranging from 0.42 to $2.8 \mathrm{~g} / \mathrm{l}$. Virological studies were all negative. The CSF level of basic protein measured in one patient 24 hours after appearance of the first signs was normal. In two patients, high levels were recorded 2 to 4 months after onset. In patient 9 , it remained normal 4 weeks after onset, although he died a few months later (table).

Technetium brain scan showed, in two of four patients, diffuse uptake in the white matter, 1 and 2 weeks respectively after onset. The one angiography performed was normal. CT scan performed in four patients less than 2 months after onset disclosed in three cases symmetrical hypodensity of the white

Table Basic protein $(\mathrm{pg} / \mathrm{ml})$

\begin{tabular}{llllll}
\hline Days & 1 & 15 & 30 & 60 & 120 \\
\hline Patient 3 & 0 & - & 1500 & 580 & - \\
Patient 5 & - & 1336 & - & - & - \\
Patient 4 & - & -0 & - & - & - \\
Patient 9 & - & - & - & - & 0 \\
\hline
\end{tabular}



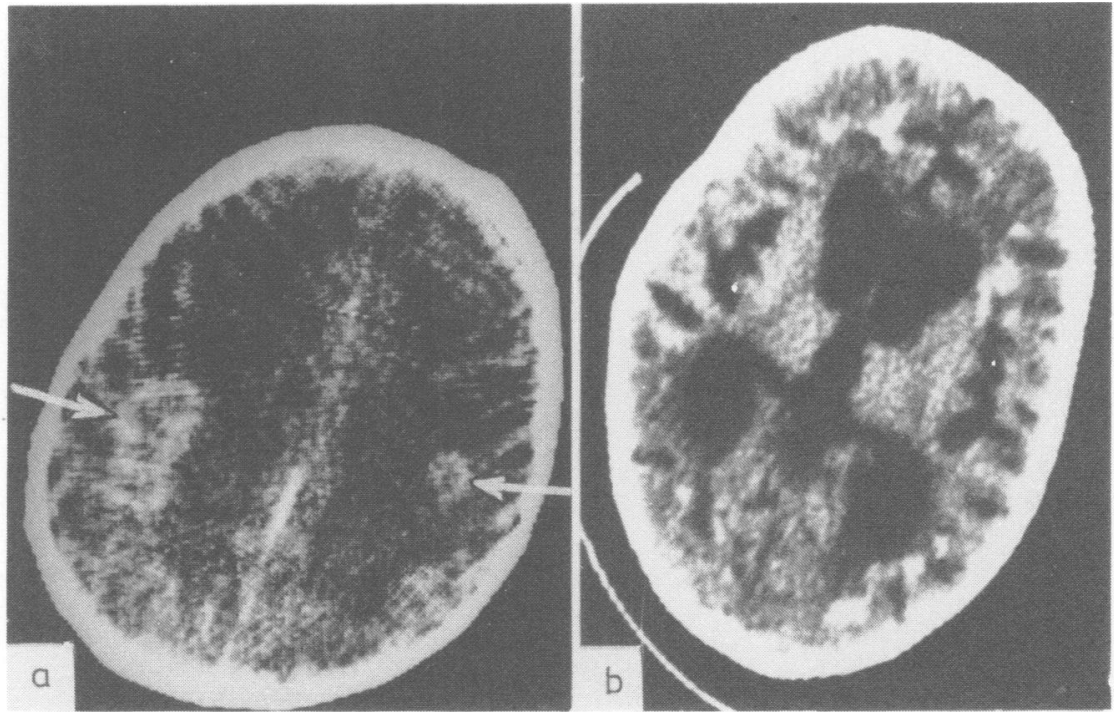

Fig 2 (A) CT Scan patient 4, 2 weeks after onset of neurological signs. Notice diffuse hypodensity of the white matter, non visibility of the lateral ventricles, and contrast enhancement disseminated in the white matter (arrows). (B) CT Scan patient 4, 6 months after (A). Notice dilated ventricles, widened sulci and areas of calcification in the depths of sulci.

matter and in two cases localised contrast enhancement of one or a few limited areas of the white matter (fig 2A). In two of these patients, CT scan repeated over 6 months after onset disclosed subcortical calcification near the base of the sulci and considerable dilatation of the ventricules (fig 2B).

The evolution was clearly different according to the age at the time of onset of the haematological treatment. In the six patients aged under 5 years, the period of progressive worsening lasted 1 to 2 months and was followed by stabilisation and later by progressive improvement after the 3rd and 4th month of evolution. However, in all patients, severe sequelae persisted, consisting either of severe mental impairment in three patients, of whom one died of haematological relapse, or of vegetative state in three patients, of whom one died 6 months later without apparent haematological relapse. In the three older patients, progressive deterioration resulted in vegetative state and death 7 weeks to 8 months after onset.

\section{CORRELATION WITH THE HAEMATOLOGICAL TREATMENT}

Details of the haematological treatment were available for six patients. The neurological complications appeared after 3 to 20 administrations of vincristine and after 5 to 53 administrations of intrathecal methotrexate. The delay from the last administration to onset of the neurological complication ranged from 5 days to 4 months for vincristine and from 5 days to 8 months for intrathecal methotrexate. The neurological signs appeared 3 to 11 months after completion of the radiotherapy (fig 1).

\section{NEUROPATHOLOGICAL STUDIES}

In patient 8 the brain weighed $1,320 \mathrm{~kg}$. The meninges were thin and transparent. Several small greyish areas were present, disseminated in the centrum semi-ovale. Microscopically, the lesions were located in the white matter and were of variable severity. They ranged from a simple myelin pallor easily seen in the anterior part of the centrum semi-ovale, to complete necrosis sometimes becoming cavitated. Eosinophilic aggregates existed, in small well-limited areas 2 to $3 \mathrm{~mm}$ diameter; silver staining by Bodian's method showed spherical or oval appearances corresponding to axonal swellings. A few lipid phagocytes, intermingled with these eosinophilic bodies, appeared concentrated around the remaining vessels. In addition to these focal softenings, many small areas of tissue disintegration appeared, centred on a small vessel with an often thickened and hyalinised wall. The perivascular space was then occupied by a cuff of mononuclear cells, but more often by red cells intermingled with fibrinous exudates and by a periadventitial fibrosis.

A few points should be stressed: The vessels within and at the periphery of the areas of necrosis were numerous and showed marked alterations: their walls were thickened, hyalinsed and occasionally infiltrated by mononuclear cells. Their lumen was sometimes narrowed by endothelial proliferation. Complete thrombosis was very rare (fig 3 ). Very many small rounded areas of calcification could be seen. This did not infiltrate the walls of the vessels, but sometimes impregnated the recognisable glial and neuronal cell processes. Axonal swellings were quite numerous, not only in the areas of 


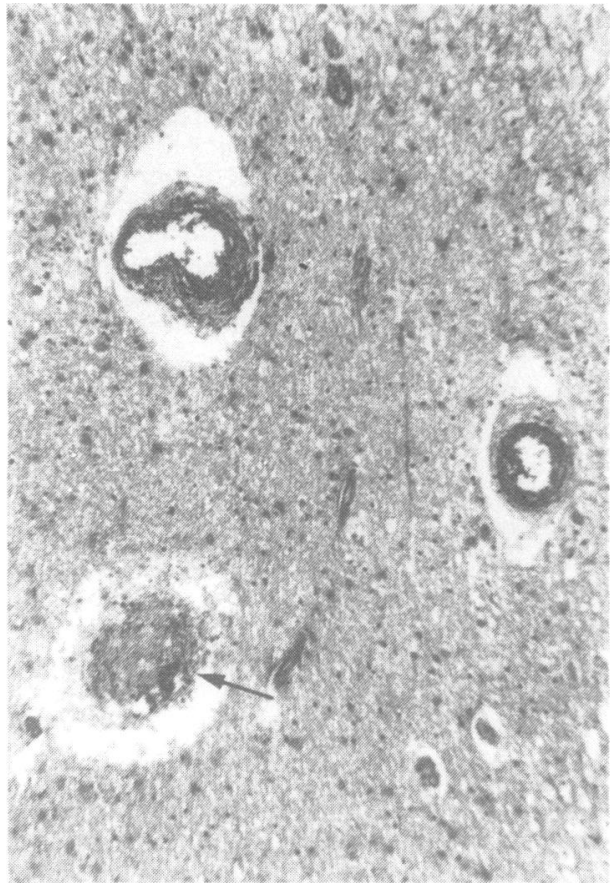

Fig 3 Patient 8-Centrum semiovale showing thrombosis in a small vessel (arrow) and periadventitial fibrosis around to other vessels. $H$ and $E \times 140$.

softening, but also disseminated in small aggregations particularly in the pes of the pons (fig 4).

Topographically, the lesions were numerous and non-coalescent. Small round areas of softening could be seen far from the ventricles, in the white matter of superior frontal, orbital, and superior and middle temporal gyri. Near the ventricle, particularly around the occipital horn, there was a narrow strip of necrosis reaching the ependymal wall (fig 5), the epithelium of which was widely destroyed.

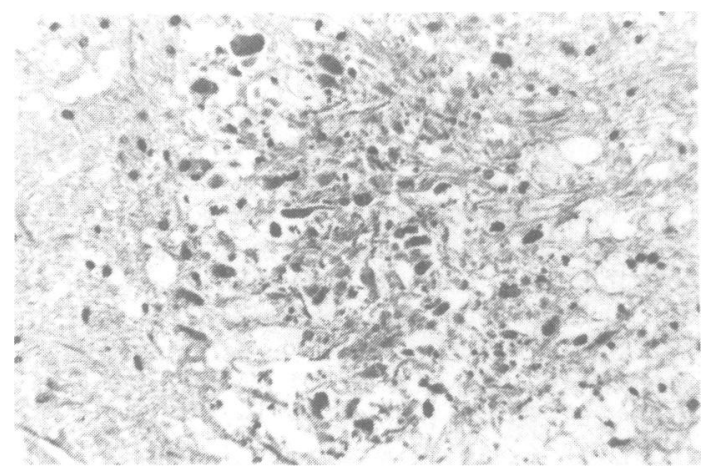

Fig 4 Patient 8-Pes of the pons. Aggregation of rounded or oval axonal swellings. $H$ and $E \times 200$.

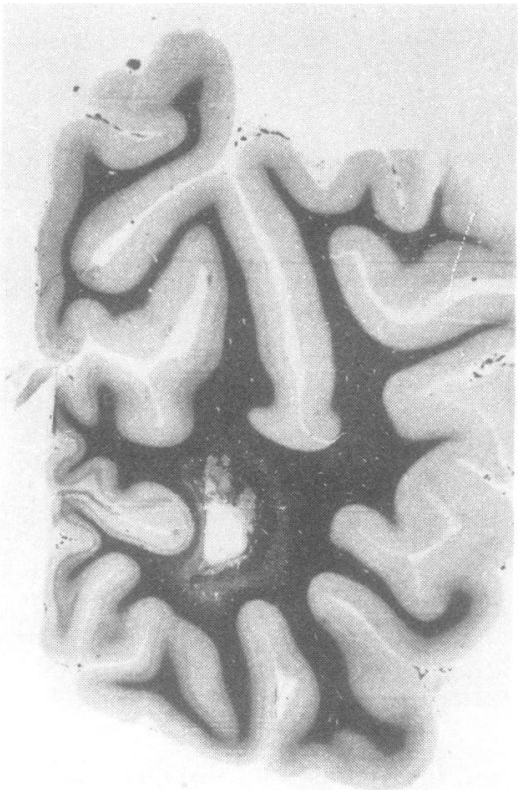

Fig 5 Patient 8-Necrosis around the occipital horn. Loyez stain for myelin $\times 1$.

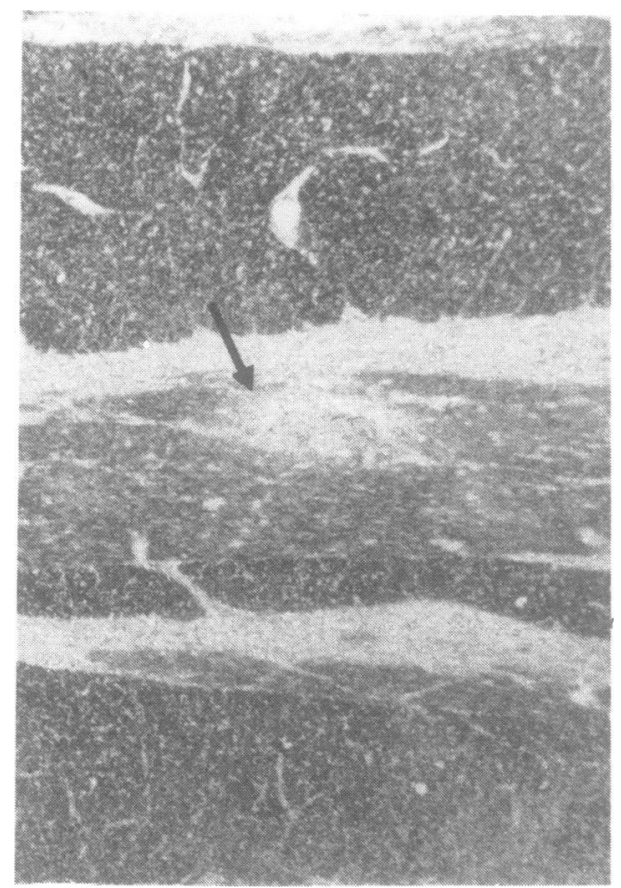

Fig 6 Patient 8-Pons. Note a small area of myelin disintegration interrupting pontocerebellar fibres (arrow). Luxol fast blue $\times 55$. 
Further out, the tapetum was preserved but was circumscribed by a second strip of myelin pallor involving thalamic radiations. The basal ganglia were normal, except for a small softening in the superoexternal part of the left putamen. In the cerebellum, several foci of confluent necrosis were present in deep white matter, whereas the white matter of the folia was mostly preserved. In the brain stem, a cystic softening occupied the right part of the tegmentum of the midbrain and extended into the brachium conjunctivum. Several small foci of myelin disintegration partially interrupted the ponto-cerebellar fibers (fig 6), and, even more so, the corticospinal tracts. In the spinal cord, both lateral pyramidal corticospinal tracts showed clear loss myelin and gliosis.

In summary, patient 8 necropsy revealed multifocal necrotising leukoencephalopathy was present with vascular lesions, even far from the necrotic areas. The perivascular topography of many areas of tissue disintegration was striking (fig 7). The spinal cord showed degeneration secondary to interruption of the corticospinal tracts.

The two other cases differed from the first only by the severity and the diffuseness of the lesions. In patient 9, the white matter lesions appeared diffuse macroscopically especially anteriorly where the

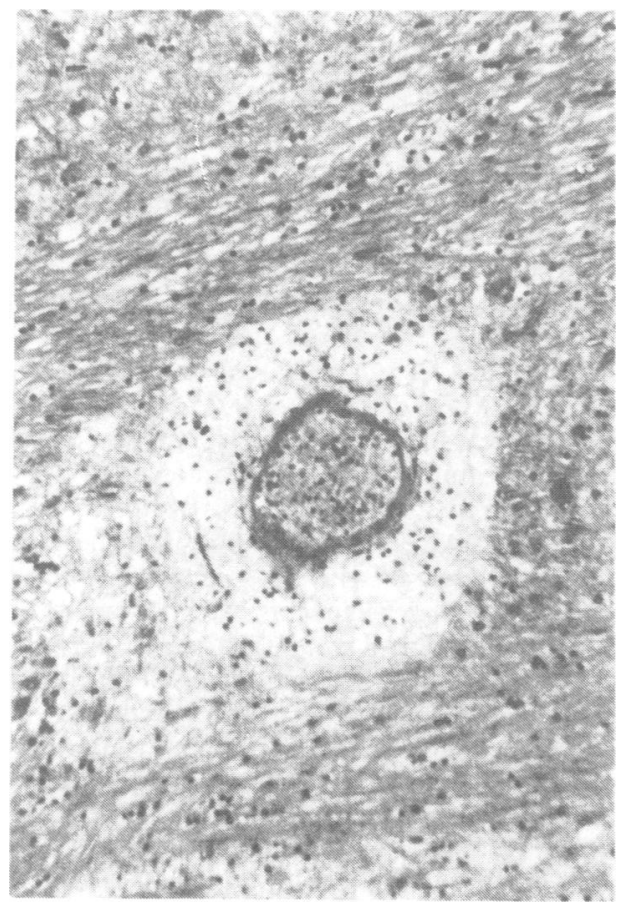

Fig 7 Patient 8 -Centrum semiovale. Perivascular collection of fat-granule cells around a small vessel. $H$ and $E \times 295$. white matter was greyish and soft. In case 8 , the vascular lesions showed predominantly periadventitial fibrosis, perivascular exudates of fibrin and red cells. Calcification was particularly marked, in the centre of the necrosed area. A few aggregations of axonal swellings could be seen, especially in the brain stem. The lesions were widespread in the centrum semi-ovale, especially in its anterior part (fig 8) and spared the occipital region. In the cerebellum, they destroyed the major part of the white matter. In the brain stem, they were more discrete, reduced to small areas of myelin destruction involving particularly the pontocerebellar fibres. The spinal cord was normal.

In patient 7 , the lesions were particularly severe. Macroscopically there was a strikingly excavated appearance of necrotic areas with serpiginous borders, disseminated through the centrum semi-ovale and predominating in the anterior part. The vascular lesions were severe and identical to those of patients 8 and 9 , with numerous vascular and perivascular mononuclear cell cuffs. There was no calcification and the aggregations of axonal retraction balls were quite numerous. The lesions were distributed through the anterior and medial part of the centrum semi-ovale (fig 9), more limited in the temporal and occipital regions. Small foci of softening were also found in the hila of the nucleus dentatus, the

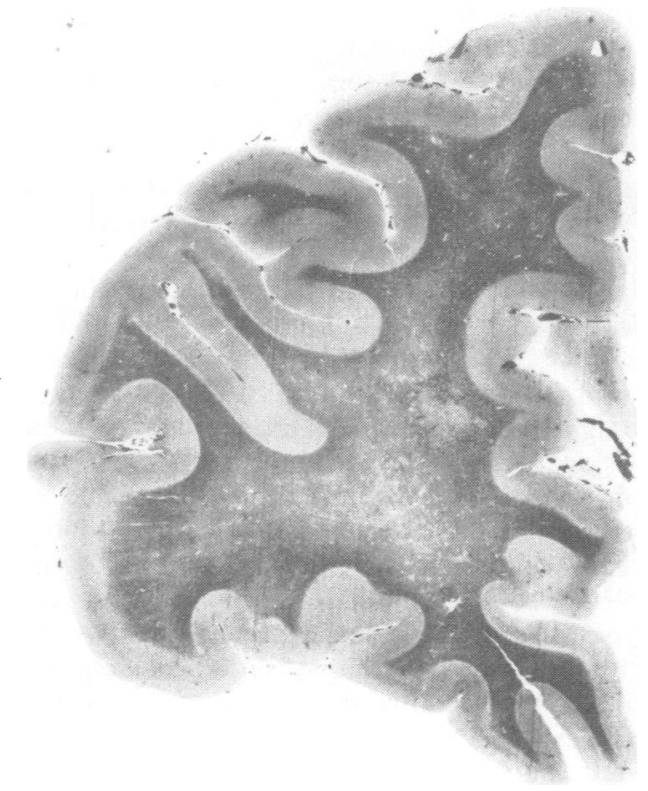

Fig 8 Patient 9-Frontal lobe: diffuse loss of myelin with some areas of cystic necrosis. Loyez $\times 1$. 


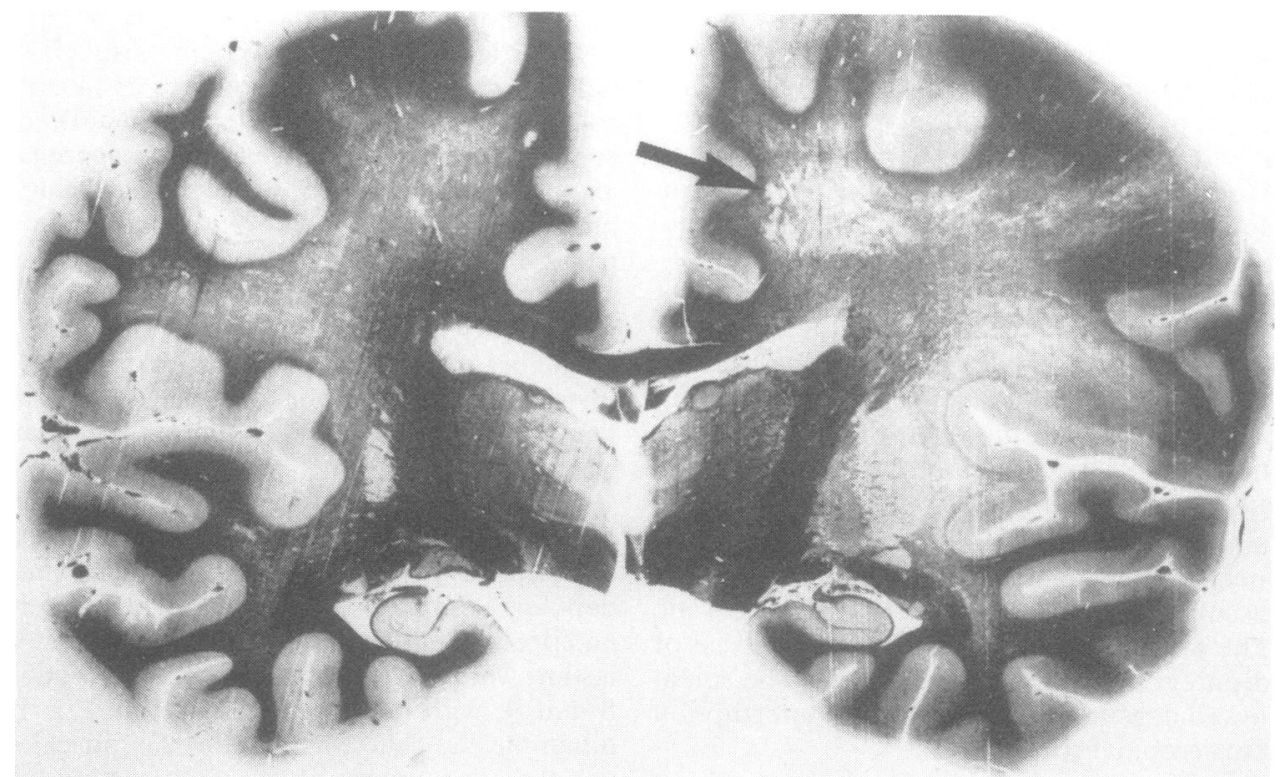

Fig 9 Patient 7-Diffuse pallor of myelin of the centrum semiovale with cystic cavitation in the right hemisphere (arrow). Loyez.

brachium conjunctivum and the brachium pontis. The cortex and the basal ganglia were spared.

\section{Discussion}

Among the various neurological complications of acute leukaemia, leukoencephalopathy has a constant pattern and its diagnosis can be made during life. Indeed, the pattern shown by the disease in the cases of Bleyer and Griffin, ${ }^{7}$ De Vivo et al ${ }^{8}$ Hendin et al, ${ }^{14}$ Kay et al, ${ }^{3}$ Rosemberg, ${ }^{9}$ Rubinstein et al, ${ }^{14}$ and ours is very similar.

Clinically there is progressive psychomotor deterioration. Convulsions are very rare and were not seen in our patients. The onset is usually so precise and the symptomatology so characteristic that the diagnosis should be suggested when a patient in remission of acute leukaemia suffers from speech impairment and behavioural changes. The most simple and reliable diagnostic tool is undoubtedly CT scan which shows white matter hypodensity. ${ }^{7}$ Localised contrast enhancement ${ }^{10}$ should not be confused with lymphoblastic infiltration. ${ }^{15}$ We therefore believe that brain biopsy is not necessary for the diagnosis; furthermore it may give negative results in cases with focal lesions (patient 8). Gangji et al ${ }^{16}$ claimed that CFS basic protein level may be an early and reliable diagnostic and prognostic tool. However, in our short experience, it seems to have limited value: high levels were inconstant and of delayed appearance.

The neuropathological pattern was also very characteristic in our cases and in those of the literature. ${ }^{46891417}$ Indeed, all these observations show more or less coalescent foci of coagulation necrosis, especially affecting the white matter. In our cases, the striking white matter predominance of the lesions was clearly shown in the pons where circumscribed areas of demyelination affected the ponto-cerebellar fibres whereas the neurons of the pontine nuclei were spared (fig $2 \mathrm{~A}$ ).

The vascular lesions were very clear in our three cases and in those of De Vivo et al ${ }^{8}$ and Rosemberg; ${ }^{9}$ however, they seem to be inconstant since Rubinstein et al,${ }^{4}$ Smith $^{17}$ and Price and Jamieson, ${ }^{6}$ also described areas of myelin loss without vascular lesions. However, Smith ${ }^{17}$ emphasised the fact that the demyelinated areas were somewhere centred on a vessel, therefore suggesting a vascular aetiology. Similar pathological manifestations have been reported in Binswangers encephalopathy. ${ }^{20}$

The axonal swellings are not specific since they also can be encountered at the periphery of the areas of softening and in various neurological or non neurological diseases. ${ }^{18}$ However, they are particularly numerous in leukoencephalopathy, as mentioned by Rubinstein $\mathrm{et} \mathrm{al}^{4}$ and in our cases some of them were observed outside of the necrotic areas (fig 2B).

The anatomical aspect of leukoencephalopathy 
can easily be distinguished from that of progressive multifocal leukoencephalopathy particularly since there are no bizarre astrocytes, so characteristic of that disease. ${ }^{19}$

Treatment is usually assumed to be responsible, but the multiplicity of drugs used makes it difficult to determine the causative drug. The precise mechanisms involved are not generally agreed. The first publication by Kay et $a^{3}$ suggested that methotrexate was responsible, inferring folinic acid treatment. However, it must be noted that spontaneous clinical improvement of leukoencephalopathy may sometimes be observed without folinic treatment (patient 4). Furthermore in nearly all cases many other drugs and radiotherapy had also been administered, except for one of Meadows and Evans cases, ${ }^{21}$ (but in this case demyelination and gliosis were observed on brain biopsy, which is insufficient to diagnose necrotising leukoencephalopathy). In our cases there was no correlation between the dose and delay after intrathecal methotrexate administration. The spinal cord was spared in two of our cases and in those of Rubinstein $\mathrm{et} \mathrm{al}^{4}$ in which it was studied. This is an argument against local effect of intrathecal methotrexate, which may induce acute paraplegia. ${ }^{22}{ }^{23}$ The type of lesion is completely different from that observed in folic acid deficiency. ${ }^{24}$

That radiotherapy is responsible is suggested by many features. As in the cases of De Vivo et al, ${ }^{8}$ Rosemberg ${ }^{9}$ and Bleyer and Griffin, ${ }^{7}$ leukoencephalopathy appears after a quite regular delay following irradiation. Worsening of signs in spite of drug discontinuation is a very characteristic feature of radionecrosis. ${ }^{25}$ In fact, the rôle of radiation is especially suggested by the neuropathology, the main problem being the interpretation of the vascular lesions. These are constant and are the initial lesion in radionecrosis. Caveness ${ }^{25}$ has shown that they electively involve the endothelial cells with a break down of the blood-brain barrier, fibrinoid necrosis, perivascular exudation and mononuclear infiltration leading to foci of myelin destruction of different ages. In our three cases, the vascular lesions were very marked, very similar to those induced by radiotherapy. They were not secondary to the softening since they existed even outside areas of complete necrosis. In the literature, they were observed by Kay et al, ${ }^{3}$ Rosemberg, ${ }^{9}$ De Vivo et al ${ }^{9}$ Rubinstein $\mathrm{et} \mathrm{al}^{4}$ case 3 ; but they are inconstant and were lacking in the cases of Price and Jamieson, ${ }^{6}$ Smith ${ }^{17}$ and Rubinstein et al. ${ }^{4}$ They were not mentioned by Hendin et al..$^{14}$ The lesions are limited to the irradiated brain and spare the unirradiated spinal cord. The frequency of leukoencephalopathy increases with increasing doses of irradiation..$^{56}$

However, neither the intensity of the lesions, nor the predominance of demyelination, nor the axonal swellings can be the result of low dose radiation therapy alone. ${ }^{25}$ Price and Jamieson ${ }^{6}$ therefore suggested that radiation, as a result of the blood-brain barrier breakdown that it induces, allows methotrexate to reach myelin and to thus express its toxic effect. Experimental evidence of this mechanism has recently been obtained (Van der Kogel, cited by Bleyer and Griffin ${ }^{7}$ ). This mechanism, however, cannot be accepted for patient 9 of our series, since he received methotexate only intrathecally. The other drugs administered should also be taken into account. The axonal swellings particularly may result from vincristine administration, as suggested by Liu, ${ }^{18}$ since this drug disorganises axonal flow by binding to neurotubules. ${ }^{26}$

Whatever the precise mechanism involved, which may be better understood as a result of ongoing experimental studies, ${ }^{7}$ the major factors of risk seem to include age and radiation dose. Leukoencephalopathy appears mainly in patients under 5 years of age receiving $24 \mathrm{~Gy}$ and in those over 5 years receiving more than $30 \mathrm{~Gy}$. The use of lower radiation doses may therefore reduce the frequency of leukoencephalopathy. General administration of drugs after irradiation also represents a theoretical risk which may be reduced by shortening the duration of maintenance treatment.

\section{Addendum}

Since completion of this work, we have had the opportunity to observe two other patients, aged 9 and 13 years, respectively treated for leukemia and lymphosarcoma. Both received a $25 \mathrm{~Gy}$ cranial irradiation. The first also received vincristine, prednisone, asparaginase, cyclophosphamide, rubidomycine and nine intrathecal methotrexate administrations, six before and three after cranial irradiation. The second also received vincristine, prednisone, cyclophosphamide, methotrexate, adriamycine and asparaginase, but no methotrexate intrathecally. After a delay of 8 and 11 months, both patients developed clinical and radiological features of leukoencephalopathy, confirmed in the first case by brain biopsy. Both patients remain unchanged with a follow-up of 3 and 22 months respectively.

\section{References}

' Pochedly C. Neurotoxicity due to CNS therapy for leukemia. Med Pediat Oncology 1977;3:101-15.

${ }^{2}$ Dulac O, Fromange A, Arthuis M. Complications neurologiques des leucémies aiguës. Arch Franc Ped 1981;38:189-93.

${ }^{3}$ Kay HEM, Knapton PJ, O'Sullivan JP, Wells DG, Harris RF, Innes EH, Stuart J, Schwartz FLM, Thompson EN. Encephalopathy in acute leukemia associated with methotrexate therapy. Arch Dis Childh 1972;47:344-54. 
${ }^{4}$ Rubinstein LJ, Herman MM, Long TF, Wilbur JK. Disseminated necrotising leukoencephalopathy: a complication of treated central nervous system leukemia and lymphoma. Cancer 1975;35:291-305.

${ }^{5}$ Aur R, Kutsu O, Simone J. Leukoencephalopathy in children with acute lymphoblastic leukemia receiving preventive central nervous system therapy. Proc Am Assoc Cancer Res 1976;17:97.

- Price R, Jamieson PA. The central nervous system in childhood leukemia. Cancer 1975;35:306-18.

${ }^{7}$ Bleyer WA, Griffin TW. White matter necrosis mineralising microangiopathy and intellectual abilities in survivors of childhood leukemias associations with control nervous system irradiation and methotrexate therapy. In: Gilbert HA and Kagan AR ed. Radiation damage to the nervous system, New York: Raven Press, 1980.

${ }^{8}$ De Vivo DC, Malas D, Nelson JS, Land VJ. Leukoencephalopathy in childhood leukemia. Neurology (Minneap) 1977;27:609-13.

${ }^{9}$ Rosemberg S. La leucoencéphalopathie. Complication du traitement des leucémies infantiles. Arch Franc Pédiat 1979;36:391-7.

${ }^{10}$ Shalen PR, Ostrow PT, Glass PJ. Enhancement of the white matter following prophylactic therapy of the central nervous system for leukemia. Radiation effects and methotrexate leukoencephalopathy. Radiology 1981;140:409-12.

"Laurian Y, Cau D, Jacque C, Breton MP, Dommergues JP, Tchernia G. Encéphalopathie après prophylaxie méningée des leucémies aiguës. Nouv Rev Fr Hematol 1981;23:291-7.

${ }^{12}$ Gerbaut L, Ponsot G, Dulac O, Olive G, Arthuis M. Profil protéique du LCR chez l'enfant. Arch Franc Ped 1981;38:3-9.

${ }^{13}$ Delassalle A, Jacques C, Drouet J, Raoul M, Legrand JC, Cesselin S. Radioimmunoassay of myelin basic protein in biological fluids, conditions improving sensitivity and specificity. Biochimie 1980;62:159-65.

${ }^{14}$ Hendin B, de Vivo DC, Torack R, Lell ME, Ragab AH, Vietti TJ. Parenchymatous degeneration of the central nervous system in childhood leukemia. Cancer 1974;33:468-81.

15 Wendling LR, Cromwell LD, Latchaw RE. Computed tomography of intracerebral leukemic masses. Am J Radiology 1979;132:217-9.

${ }^{16}$ Gangji D, Reaman GH, Cohen SR, Bleyer WA, Poplack DG. Leukoencephalopathy and elevated levels of myelin basic protein in the cerebrospinal fluid of patients with acute lymphoblastic leukemia. $N$ Engl $J$ Med 1980;303:19-23.

${ }^{17}$ Smith B. Brain damage after intrathecal methotrexate. $J$ Neurol Neurosurg Psychiatry 1975;38:810-5.

${ }^{18}$ Liu HM. Reactive neuroaxonal dystrophy in children. Acta Neuropath (Berl) 1978;42:237-41.

${ }^{19}$ Richardson EP. Progressive multifocal leukoencephalopathy: In: Vinken PJ and Bruyn GW eds. Handbook of Clinical Neurology. Vol. 9 Chap. 18. North Holland Publishing Company, Amsterdam 1970.

${ }^{20}$ Loizou LA, Jefferson JM, Smith WT. Subcortical arteriosclerotic encephalopathy (Binswanger's type) and cortical infarcts in a young normotensive patient. J Neurol Neurosurg Psychiatry 1982;45:409-17.

${ }^{21}$ Meadows AT, Evans AE. Effects of chemotherapy on the central nervous system. Cancer 1976;37:1079-85.

${ }^{22}$ Gagliano RG, Costunzi JJ. Paraplegia following intrathecal methotrexate. Report of a case and review of the literature. Cancer 1976;37:1663-8.

${ }^{23}$ Clark AW, Cohen SR, Nissenblatt MJ, Wilson SK. Paraplegia following intrathecal chemotherapy. Cancer 1982;50:42-7.

${ }^{24}$ Smith WT. Nutritional deficiencies and disorders: In: Greenfield's Neuropathology, 3rd Ed. London: Edward Arnold, 1976.

${ }^{25}$ Caveness WF. Experimental observations: delayed necrosis in normal monkey. In: Gilbert HA, Kagan AR, eds. Radiation damage to the Nervous System. New York, Raven Press 1980.

${ }^{26}$ Wisniewski H, Shelanski ML, Terry RD. Effects of mitctic spindle inhibitors on neurotubules and neurofilaments of anterior horn cells. $J$ Cell Biol 1968;38:224-9. 